\title{
Regular and low-dose aspirin, other non- steroidal anti-inflammatory medications and prospective risk of HER2-defined breast cancer: the California Teachers Study
}

Christina A. Clarke ${ }^{1,2}$, Alison J. Canchola ${ }^{1}$, Lisa M. Moy ${ }^{1,4}$, Susan L. Neuhausen ${ }^{3}$, Nadia T. Chung ${ }^{3}$, James V. Lacey Jr $\mathrm{r}^{3}$ and Leslie Bernstein ${ }^{3^{*}}$

\begin{abstract}
Background: Regular users of aspirin may have reduced risk of breast cancer. Few studies have addressed whether risk reduction pertains to specific breast cancer subtypes defined jointly by hormone receptor (estrogen and progesterone receptor) and human epidermal growth factor receptor 2 (HER2) expression. This study assessed the prospective risk of breast cancer (overall and by subtype) according to use of aspirin and other non-steroidal anti-inflammatory medications (NSAIDs) in a cohort of female public school professionals in California.

Methods: In 1995 - 1996, participants in the California Teachers Study completed a baseline questionnaire on family history of cancer and other conditions, use of NSAIDs, menstrual and reproductive history, self-reported weight and height, living environment, diet, alcohol use, and physical activity. In 2005-2006, 57,164 participants provided some updated information, including use of NSAIDs and 1457 of these participants developed invasive breast cancer before January 2013. Multivariable Cox proportional hazards regression models provided hazard rate ratios (HRR) for the association between NSAID use and risk of invasive breast cancer as well as hormone receptor- and HER2-defined subtypes.

Results: Developing breast cancer was associated inversely with taking three or more tablets of low-dose aspirin per week (23\% of participants). Among women reporting this exposure, the HRR was 0.84 (95\% confidence interval (CI) 0.72-0.98) compared to those not taking NSAIDs and this was particularly evident in women with the hormone receptor-positive/HER2-negative subtype ( $\mathrm{HRR}=0.80,95 \% \mathrm{Cl} 0.66-0.96)$. Use of three or more tablets of "other" NSAIDs was marginally associated with lower risk of breast cancer (HRR $=0.79,95 \% \mathrm{Cl} 0.62-1.00)$. Other associations with NSAIDs were generally null.

Conclusion: Our observation of reduced risk of breast cancer, among participants who took three or more tablets of low-dose aspirin weekly, is consistent with other reports looking at aspirin without differentiation by dose. This is the first report to suggest that the reduction in risk occurs for low-dose aspirin and not for regulardose aspirin and only among women with the hormone receptor-positive/HER2-negative subtype. This preliminary study builds on previous knowledge and further supports the need for formal cancer chemoprevention studies of low-dose aspirin.
\end{abstract}

Keywords: Aspirin, NSAIDs, Breast cancer, Hormone receptor, HER2, Subtype, Epidemiology

\footnotetext{
*Correspondence: Ibernstein@coh.org

${ }^{3}$ Department of Population Sciences, Beckman Research Institute of City of

Hope, 1500 East Duarte Rd, Duarte, CA 91010, USA

Full list of author information is available at the end of the article
} 


\section{Background}

Daily use of low-dose $(81 \mathrm{mg})$ aspirin is formally recommended by the United States Preventive Services Task Force (USPSTF) for broad chemoprevention of cardiovascular disease [1] and colorectal cancer [2]. Regulardose aspirin may also provide effective chemoprevention of breast cancer in women, although the evidence is mixed. In one clinical trial in which women were randomized to receive $100 \mathrm{mg}$ of aspirin or placebo every other day, no reduction in breast cancer risk was observed among women receiving aspirin [3]. However, a meta-analysis published in 2008, which included 38 studies and over 2 million women, concluded that breast cancer risk overall was reduced in association with use of any aspirin or other non-steroidal anti-inflammatory drugs (NSAIDs) [4]. In contrast, in a more recent assessment of 32 studies the authors concluded that aspirin use was not associated with risk of breast cancer, although a statistically significant reduction in the risk of hormone receptor (HR)-positive subtypes was noted [5]. Both of these meta-analyses detected substantial heterogeneity of results among studies [4, 5]. One contributor to this heterogeneity may be variation in associations by breast cancer subtype, defined jointly by $\mathrm{HR}$ and HER-2/neu receptor (HER2) status. Tumor expression of these markers strongly influences clinical care (e.g., treatment with tamoxifen or trastuzumab) and is also associated with marked differences in incidence patterns and risk factors [6-9]. It is possible that NSAIDs differentially influence the development of tumors based on the expression of HR and HER2. Heterogeneity in the results for aspirin may also be explained by previous studies not distinguishing between low-dose or daily aspirin use, which are common patterns of NSAID use that may be misclassified in broader categorizations, such as all doses of aspirin combined or use of three or more tablets per week.

To date, one prospective and two case-control studies have examined detailed use of NSAIDs and risk of breast cancer subtypes defined jointly by HR and HER2 status. The Nurses' Health Study reported that use of two or more tablets of any dose of aspirin per week was statistically significantly associated with the risk of the luminal A (HR-positive/HER2-negative) subtype but not associated with the luminal B subtype (HR-positive/HER2positive), indicating the importance of categorizing HER2 in detail [10]. In the two case-control studies any aspirin use was statistically significantly associated with reductions in risk of all four breast cancer subtypes studied $[11,12]$ and one of these studies further suggested that reductions in risk were limited to overweight women [12], in whom adipose-related inflammation might be higher.
To add to the evidence on low-dose aspirin, other NSAIDs including regular dose aspirin (defined as $325 \mathrm{mg}$ ), and the risk of HR and HER2-defined breast cancer subtypes, we looked to our long-term prospective cohort of California public school professionals who were asked in 2005-2006 about current use of painrelieving medications, including low-dose aspirin, regular-dose aspirin, ibuprofen, and other NSAIDs. A prior analysis of NSAIDS and breast cancer in this cohort [13] was based on earlier questionnaire data that did not differentiate between low-dose and regular-dose aspirin. With over 7 years of follow up of incident breast cancer $(n=1457)$ including crucial detail on tumor HER2 status since submission of the 2005-2006 questionnaire, we evaluated whether risk of breast cancer varied by recent use of NSAIDs, and explored whether any associations between NSAIDs and risk of breast cancer were modified by HER2-defined breast cancer subtypes or overweight status.

\section{Methods}

The California Teachers Study cohort (CTS) was established in 1995-1996 when 133,479 active and retired female teachers, administrators and other public school professionals were recruited through the California State Teachers Retirement System [14]. Participants completed a baseline questionnaire that collected information on family history of cancer and other conditions, menstrual and reproductive history, self-reported weight and height, living environment, diet, alcohol and tobacco use, physical activity history, and frequency and duration of prior use of certain medications including aspirin (but without detail on aspirin dose).

In 2005-2006, a 10-year follow-up questionnaire collected updated information on frequency of current use of aspirin, low-dose aspirin and other pain-relieving medications (see below), weight, alcohol use, menopausal status, use of hormone therapy (HT), and physical activity. Copies of questionnaires are available at https://www.calteachersstudy.com/past-questionnaires.

The CTS is overseen by the Institutional Review Boards of the Cancer Prevention Institute of California, the California Health and Human Services Agency, the University of California, Irvine, the University of Southern California, and the City of Hope.

CTS participants are followed annually for changes of address, cancer diagnoses, hospitalizations, outpatient surgeries, emergency room visits, and death. Annual linkage with the California Cancer Registry (CCR) is used to identify incident cancer among cohort members. The CCR is a population-based cancer registry, which is anchored in state legislation that mandates reporting and is estimated to be over 99\% complete [15]. Annual linkages with the Office of Statewide Health Planning 
and Development (OSHPD) allow us to identify details of each members' hospitalizations, outpatient surgeries, and emergency room visits. California and national mortality files are used to ascertain dates and causes of death.

\section{Breast cancer ascertainment}

Information on all incident breast cancers was obtained from the CCR, including pathologic and clinical features, which are abstracted directly from the medical record. HR status was based on estrogen receptor (ER) and progesterone receptor (PR) status as routinely reported on diagnostic pathology records. HER2 status was also based on pathology report review. Subtypes were defined as follows: HR-positive/HER2-negative was defined as ER-positive or PR-positive and HER2-negative; HRpositive/HER2-positive was defined as ER-positive or PR-positive and HER2-positive; HR-negative/HER2-positive was defined as ER-negative and PR-negative and HER2-positive; and triple-negative was defined as ERnegative, PR-negative, and HER2-negative.

\section{Assessment of pain-relieving medications}

On the 10-year follow-up questionnaire, women were asked whether they were currently taking any painrelieving medications at least once a week, and if yes, the total number of tablets taken per week $(1-2,3-4$, $5-6,7-8,9-10,11-12,13-14,15-21,22-28$, or $29+$ tablets per week). The medication choices included low-dose aspirin; aspirin or aspirin-containing product (Bayer, Bufferin, Excedrin); ibuprofen (Advil, Motrin); naproxen, ketoprofen or other non-steroidal (Aleve, Feldene, Indocin, Naprosyn, Orudis, Relafen); Cox-2 inhibitors (Celebrex, Vioxx); and acetaminophen (aspirin-free Excedrin, Tylenol, Tempra). Women were then asked if they had stopped regular use of any of these medications during the past 3 years, and if yes, why (by marking any of the following response categories that applied: "Condition improved", "Didn't work", "I had side effects", "I heard about side effects", "Drug no longer available", "Other"). The baseline questionnaire asked if aspirin (Anacin, Bufferin, Excedrin) and ibuprofen (Advil, Motrin, Nuprin) were taken regularly (at least once a week), total years taken and how many days per week taken (1-3 days/week, 4-6 days/week or daily).

Each medication type from the 10-year questionnaire was initially categorized as "Never in the past 3 years", "Former", "Current" ,or "Unknown" for that type of medication. Women were classified into the category "Never in the past 3 years" if they reported: (1) current use of 0 or $<1$ medication per week or left this question blank; (2) never took the medication regularly or did not stop regular use or left this question blank; and (3) did not give a reason for stopping. "Current" users were those who reported: (1) current use of $\geq 1$ tablet(s) per week; (2) "Never took regularly or did not stop use" or left this question blank; and (3) did not give a reason for stopping. "Former" users were those who reported: (1) "Yes, I stopped regular use" or gave a reason for stopping; and (2) reported current use as 0 or $<1$ medication per week or left this question blank. All other women, including those whose answers were inconsistent or who left both questions blank for all medications, were classified as "Unknown".

For analysis, we: (1) focused on the five NSAIDs from the 10-year questionnaire, excluding acetaminophen; (2) grouped the women who were in the category of "Never in the past 3 years" for the medication of interest into women who reported (a) "No NSAIDs in the past 3 years," which was used as the reference group, (b) no use of that particular type of medication but had used one or more of the other four NSAIDs in the past 3 years, and (c) no use of that particular type of medication and unknown use of one or more of the other four NSAIDS, which was combined with the "Unknown" category; and (3) combined former and current users of 1-2 tablets per week into one category. For low-dose aspirin, we also examined "Daily" use, which was defined as those with current use of $7+$ tablets per week (Table 2).

\section{Study population}

For the present analyses, we excluded women sequentially who at baseline were not residing in California $(n$ $=8867)$, had a prior history of breast cancer $(n=6216)$, or had unknown cancer history $(n=135)$. We also excluded women who prior to the 10-year follow-up questionnaire had died $(n=8654)$, had requested no further contact from the CTS $(n=926)$, had moved out of California for more than 4 months $(n=8296)$, had developed breast cancer $(n=4188)$, or had a bilateral mastectomy without a diagnosis of breast cancer (identified from hospital discharge data) $(n=18)$. Among the remaining 96,179 participants, 57,164 (59\%) completed the 10-year follow-up questionnaire. During follow up (from the date a woman completed the 2005-2006 questionnaire and continuing through 31 December 2012), 1457 women were diagnosed with invasive breast cancer after completing the 10-year follow-up questionnaire.

\section{Data analysis}

Follow-up time was calculated as the number of days between the date the 10-year follow-up questionnaire was completed and the first of the following events: a first diagnosis of breast cancer (International Classification of Diseases for Oncology-3 (ICD-O-3) site code C50) $(n=$ 1457 with invasive cancer; $n=393$ in situ cancer), death 
( $n=3538$ ), a move (for $>4$ months) out of California ( $\mathrm{n}$ $=2082)$, bilateral mastectomy $(n=5)$, or 31 December $2012(\mathrm{n}=49,689)$.

Hazard rate ratios (HRR) and 95\% CI were estimated using multivariable Cox proportional hazards regression models, with age (in days) as the time metric and stratification by age (in years) at the time of the 10-year follow-up questionnaire. Covariates were included based on their independent association with risk for a given outcome with a $p$ value $<0.05$ in multivariable models.

Competing risk analysis was used to estimate risk of invasive breast cancer overall and by different receptor subtypes. The 157 women diagnosed with breast cancer during follow up who had missing information on HR or HER2 status were excluded from all models with breast cancer subtype as the outcome. We tested the proportional hazards assumption for each covariate in the model and for the main effect for the different outcomes using a likelihood ratio test of interaction with the time metric (continuous age) based on cross-product terms. We found only one violation of the proportional hazards assumption: alcohol consumption had a statistically significant interaction with time-dependent age for HRnegative/HER2-negative tumors; thus, this interaction was included in the model for that outcome.

We conducted multivariable analyses in which we assessed the impact of adjusting for history of hospitalization for myocardial infarction (between 1991 and the date the 10-year follow-up questionnaire was completed based on ICD-9 diagnostic codes 410.00410.92 from OSHPD linkage; no, yes) and history of diabetes mellitus (from the 10-year follow-up questionnaire; no, yes, missing). These adjustments did not meaningfully change the HRR when evaluating the association of current use of low-dose aspirin with risk of breast cancer overall or with risk of any of the receptor subtypes. Hence, history of myocardial infarction and history of diabetes mellitus were not included in the final models presented here. We also examined models of low-dose aspirin stratified by body mass index (BMI) $(<25$ or $\geq 25 \mathrm{~kg} / \mathrm{m}^{2}$ ) and tested the interaction using a likelihood ratio test and cross-product terms, excluding women with unknown NSAID use.

In a secondary analysis, we considered aspirin use at baseline (regular-dose and low-dose aspirin were not asked about separately) in conjunction with use of regular-dose and low-dose aspirin from the 10-year questionnaire, with no NSAID use reported at both baseline (including aspirin and ibuprofen) and the 10year follow-up (including regular-dose and low-dose aspirin, ibuprofen, Cox-2 inhibitors, and other NSAIDs) as the reference group. This analysis was limited to outcomes of breast cancer and the HR-
positive/HER2-negative subtype, as we had an insufficient number of diagnoses to examine these associations in the other subtypes.

\section{Results}

The 1457 cases of invasive breast cancer diagnosed during follow up included 998 (68\%) HR-positive/HER2negative, 120 (8\%) HR-positive/HER2-positive, 44 (3\%) HR-negative/HER2-positive, 138 (9\%) HR-negative/HER2negative breast cancers, and 157 (11\%) with missing data on expression status for at least one receptor. The characteristics of cohort participants are shown in Table 1: the majority of participants (88\%) were of non-Hispanic, white ethnicity and the median age at the time of the 10-year follow-up survey was 61 years (interquartile range 54-71 years). Participants had a relatively high prevalence of some of the established risk factors for breast cancer, with $20 \%$ reporting current use of HT and 15\% reporting current consumption of $\geq 20$ g of alcohol per day.

The most common NSAID reported as currently used by participants at the 10-year follow-up was low-dose aspirin (Table 1); 23\% of women reported current use of at least three low-dose aspirin tablets per week. Ibuprofen was the second most common pain-relieving medication used, with $18 \%$ of participants reporting use of at least three tablets per week. Use of at least three regulardose $(325 \mathrm{mg})$ aspirin tablets per week was reported by $11 \%$ of the CTS participants. Less than $10 \%$ of participants reported current use of other NSAIDs or COX-2 inhibitors.

Current use of at least three tablets per week of any NSAID was not statistically significantly associated with any particular subtype of breast cancer or breast cancer overall (Table 2). However, when low-dose aspirin was considered separately, current use of three or more tablets per week of low-dose aspirin was statistically significantly associated with risk of breast cancer overall (HRR $=0.84,95 \%$ CI $0.72-0.98$ compared to those not taking any NSAIDS); this association was observed only for the HR-positive/HER2-negative subtype (HRR $=0.80,95 \%$ CI 0.66-0.96). Considering more granular categories of frequency of low-dose aspirin use, relative to women who had not used any NSAID in the past 3 years, an inverse association with breast cancer risk was observed among women using 3-6 tablets per week $(\mathrm{HRR}=$ $0.72,95 \%$ CI $0.54-0.96)$ and a marginal association was observed among those using $7+$ tablets per week $(\mathrm{HRR}=0.87,95 \%$ CI 0.74-1.02). A similar pattern of inverse association was observed for the HR-positive/ HER2-negative breast cancer subtype (for 3-6 tablets/ week, $\mathrm{HRR}=0.66,95 \% \mathrm{CI} 0.47-0.94$; for $7+$ tablets $/$ week, $\mathrm{HRR}=0.83,95 \%$ CI $0.68-1.01$, data not shown). We also observed a lower risk of breast cancer among women who reported current use of "other" NSAIDs 
Table 1 Participant characteristics and use of non-steroidal antiinflammatory medications, California Teachers Study, 2005-2012

\begin{tabular}{|c|c|c|}
\hline Characteristic & Number & Percentage \\
\hline \multicolumn{3}{|l|}{ Age (years) ${ }^{a}$} \\
\hline$<40$ & 1781 & 3.1 \\
\hline $40-49$ & 7020 & 12.3 \\
\hline $50-59$ & 16,651 & 29.1 \\
\hline $60-69$ & 15,779 & 27.6 \\
\hline 70-79 & 10,482 & 18.3 \\
\hline $80-89$ & 4812 & 8.4 \\
\hline$\geq 90$ & 639 & 1.1 \\
\hline \multicolumn{3}{|l|}{ Race $^{b}$} \\
\hline White & 50,250 & 87.9 \\
\hline Hispanic & 2220 & 3.9 \\
\hline Asian/Pacific Islander & 2135 & 3.7 \\
\hline Black & 1183 & 2.1 \\
\hline Other/mixed & 972 & 1.7 \\
\hline Missing & 404 & 0.7 \\
\hline \multicolumn{3}{|l|}{ Age at menarche (years) ${ }^{b}$} \\
\hline$<12$ & 12,799 & 22.4 \\
\hline$\geq 12$ & 43,635 & 76.3 \\
\hline Missing & 730 & 1.3 \\
\hline \multicolumn{3}{|l|}{ Age at first full-term pregnancy (years) ${ }^{b}$} \\
\hline Nulliparous & 14,157 & 24.8 \\
\hline$<25$ & 15,171 & 26.5 \\
\hline$\geq 25$ & 26,909 & 47.1 \\
\hline Missing & 927 & 1.6 \\
\hline \multicolumn{3}{|l|}{ Total time breastfeeding (months) ${ }^{\mathrm{b}}$} \\
\hline Never or $<12$ & 40,567 & 71.0 \\
\hline$\geq 12$ & 15,446 & 27.0 \\
\hline Missing & 1,151 & 2.0 \\
\hline \multicolumn{3}{|l|}{ History of a benign breast biopsy ${ }^{b}$} \\
\hline No & 47,812 & 83.6 \\
\hline Yes & 9175 & 16.1 \\
\hline Missing & 177 & 0.3 \\
\hline \multicolumn{3}{|c|}{ Family history of breast cancer (mother or sister) ${ }^{b}$} \\
\hline No & 48,736 & 85.3 \\
\hline Yes & 6763 & 11.8 \\
\hline Missing data or participant was adopted & 1665 & 2.9 \\
\hline \multicolumn{3}{|c|}{ History of hospitalization for myocardial infarction ${ }^{c}$} \\
\hline No & 56,586 & 99.0 \\
\hline Yes & 578 & 1.0 \\
\hline \multicolumn{3}{|l|}{ History of diabetes mellitus ${ }^{a}$} \\
\hline No & 54,433 & 95.2 \\
\hline Yes & 2715 & 4.8 \\
\hline Missing & 16 & 0.0 \\
\hline
\end{tabular}

Table 1 Participant characteristics and use of non-steroidal antiinflammatory medications, California Teachers Study, 2005-2012 (Continued)

Strenuous plus moderate physical activity

in the past 3 years (hours per week)

$\begin{array}{lll}<3 & 26,079 & 45.6 \\ \geq 3 & 30,909 & 54.1 \\ \text { Missing } & 176 & 0.3\end{array}$

Alcohol consumption (grams per day) ${ }^{a}$

$\begin{array}{lll}\text { None or }<20 & 46,033 & 80.5 \\ \geq 20 & 8652 & 15.1 \\ \text { Missing } & 2479 & 4.3\end{array}$

Body mass index $\left(\mathrm{kg} / \mathrm{m}^{2}\right)^{\mathrm{a}}$

$\begin{array}{lll}<25.0 & 29,509 & 51.6 \\ 25.0-29.9 & 16,619 & 29.1 \\ \geq 30.0 & 10,359 & 18.1 \\ \text { Missing } & 677 & 1.2\end{array}$

Menopausal status and hormone therapy $(\mathrm{HT}) \mathrm{use}^{\mathrm{a}}$

$6314 \quad 11.1$

Perimenopausal or postmenopausal

No HT in the last 5 years $\quad 27,397 \quad 47.9$

Used HT in the last 5 years, but not $\quad 10,142 \quad 17.7$

currently using

$11,420 \quad 20.0$

Current HT use

$1891 \quad 3.3$

Unknown menopausal status or HT use

$37,075 \quad 64.9$

Regular-dose aspirin use at baseline ${ }^{b}$

No NSAID use

$7002 \quad 12.3$

No regular-dose aspirin use, but used ibuprofen

$\begin{array}{lll}\text { Used } 1-3 \text { days/week } & 6340 & 11.1 \\ \text { Used 4+ days/week } & 5732 & 10.0 \\ \text { Unknown } & 1015 & 1.8\end{array}$

Low-dose aspirin use at the 10-year follow up ${ }^{a}$

Never in the past 3 years

$\begin{array}{lll}\text { No NSAID use in the past } 3 \text { years }^{\mathrm{e}} & 21,421 & 37.5 \\ \text { No low-dose aspirin use, use of 1+ type(s) } & 15,678 & 27.4 \\ \begin{array}{l}\text { No low-dose aspirin use, unknown use of 1 } \\ + \text { type(s) }\end{array} & 1829 & 3.2 \\ \text { Former } & 2766 & 4.8 \\ \text { Current, 1-2 tablets/week } & 915 & 1.6 \\ \text { Current, 3-4 tablets/week } & 1163 & 2.0 \\ \text { Current, 5-6 tablets/week } & 1406 & 2.5 \\ \text { Current, 7+ tablets/week } & 10,421 & 18.2 \\ \text { Unknown } & 1565 & 2.7\end{array}$


Table 1 Participant characteristics and use of non-steroidal antiinflammatory medications, California Teachers Study, 2005-2012 (Continued)

\begin{tabular}{|c|c|c|}
\hline \multicolumn{3}{|l|}{ Regular-dose aspirin use at the 10-year follow up ${ }^{a}$} \\
\hline \multicolumn{3}{|l|}{ Never in the past 3 years } \\
\hline No NSAID use in the past 3 years ${ }^{\mathrm{e}}$ & 21,421 & 37.5 \\
\hline $\begin{array}{l}\text { No regular-dose aspirin use, use } \\
\text { of } 1+\text { type(s) }\end{array}$ & 23,451 & 41.0 \\
\hline $\begin{array}{l}\text { No regular-dose aspirin use, unknown use } \\
\text { for } 1+\text { type(s) }\end{array}$ & 2253 & 3.9 \\
\hline Former/irregular & 2378 & 4.2 \\
\hline Current, $3+$ tablets/week & 6387 & 11.2 \\
\hline Unknown & 1274 & 2.2 \\
\hline \multicolumn{3}{|l|}{ Ibuprofen use at the 10-year follow up ${ }^{a}$} \\
\hline \multicolumn{3}{|l|}{ Never in the past 3 years } \\
\hline No NSAID use in the past 3 years ${ }^{e}$ & 21,421 & 37.5 \\
\hline No ibuprofen use, use of 1+ type(s) & 18,219 & 31.9 \\
\hline $\begin{array}{l}\text { No ibuprofen use, unknown } \\
\text { use for } 1+\text { type(s) }\end{array}$ & 1499 & 2.6 \\
\hline Former/irregular & 3679 & 6.4 \\
\hline Current, $3+$ tablets/week & 10,382 & 18.2 \\
\hline Unknown & 1964 & 3.4 \\
\hline \multicolumn{3}{|l|}{ Other non-steroidal use at the 10 -year follow up ${ }^{a}$} \\
\hline \multicolumn{3}{|l|}{ Never in the past 3 years } \\
\hline No NSAID use in the past 3 years $^{\mathrm{e}}$ & 21,421 & 37.5 \\
\hline $\begin{array}{l}\text { No other non-steroidal use, } \\
\text { use of } 1+\text { type(s) }\end{array}$ & 25,529 & 44.7 \\
\hline $\begin{array}{l}\text { No other non-steroidal use, } \\
\text { unknown use for } 1+\text { type(s) }\end{array}$ & 2307 & 4.0 \\
\hline Former/irregular & 2301 & 4.0 \\
\hline Current, $3+$ tablets/week & 4263 & 7.5 \\
\hline Unknown & 1343 & 2.4 \\
\hline \multicolumn{3}{|l|}{ Cox-2 inhibitor use at the 10 -year follow up ${ }^{a}$} \\
\hline \multicolumn{3}{|l|}{ Never in the past 3 years ${ }^{\mathrm{e}}$} \\
\hline No NSAID use in the past 3 years $^{\mathrm{e}}$ & 21,421 & 37.5 \\
\hline No Cox-2 inhibitor use, use of $1+$ type(s) & 28,055 & 49.1 \\
\hline $\begin{array}{l}\text { No Cox- } 2 \text { inhibitor use, unknown } \\
\text { use for } 1+\text { type(s) }\end{array}$ & 2625 & 4.6 \\
\hline Former/irregular & 2807 & 4.9 \\
\hline Current, $3+$ tablets/week & 1064 & 1.9 \\
\hline Unknown & 1192 & 2.1 \\
\hline
\end{tabular}

${ }^{\mathrm{a}}$ From the 10-year follow-up questionnaire completed in 2005-2006. ${ }^{\mathrm{b}}$ From the baseline questionnaire completed in 1995-1996. ' From linkage with the Office of Statewide Health Planning and Development (OSHPD) hospital discharge database from 1991 until the 10-year follow-up questionnaire. dincluded aspirin and ibuprofen used regularly (at least once a week) reported

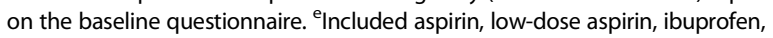
Cox-2 inhibitors, and other NSAIDs currently used regularly (at least once a week) reported on the 10-year follow-up questionnaire. NSAID non-steroidal anti-inflammatory drug
(HRR $=0.79,95 \%$ CI 0.62-1.00). Risk of HR-positive/ HER2-positive tumors was increased in those with unknown use of ibuprofen, Cox-2 inhibitors, and "other" NSAIDs, but was based on a small number of cases $(n$ $=13$ ). Significant associations did not appear to differ by overweight status ( $p$ interaction $=0.18$ for low-dose aspirin and all subtypes of breast cancer.)

To assess associations with risk of breast cancer overall and with risk of one subtype among probable longterm users of NSAIDs, we carried out secondary analyses combining information reported on the baseline and 10-year follow-up questionnaires. Among women currently using $3+$ low-dose aspirin tablets per week at the 10-year follow up, risk of breast cancer was comparable between those who reported no NSAID use at baseline $(\mathrm{HRR}=0.79,95 \%$ CI 0.66-0.95, 181 cases $)$ and those who reported using aspirin regularly for $4+$ days per week at baseline (HRR $=0.79,95 \%$ CI $0.59-1.08,50$ cases) compared to those who reported no NSAID use on both the baseline questionnaire and the 10-year follow-up questionnaire (409 cases). Results were similar for those currently using $3+$ tablets per week of regulardose aspirin at the 10-year follow-up (HRR $=0.92$, 95\% CI $0.70-1.20$ (67 cases) for no NSAID use at baseline; $\mathrm{HRR}=0.94,95 \%$ CI 0.67-1.31 (39 cases) for aspirin 4+ days per week at baseline). Similar patterns were observed for the HR-positive/HER2-negative subtype (data not shown).

To assess possible confounding by indication, we also assessed associations between breast cancer and acetaminophen, a pain reliever that is not an NSAID. Current use of at least 3 tablets per week of acetaminophen was not associated with breast cancer or any particular subtype of breast cancer in models adjusted for the five NSAIDS (for breast cancer, HRR $=1.00,95 \% \mathrm{CI}$ 0.87-1.15 for current use of $3+$ tablets per week of acetaminophen (264 cases) compared to no use of acetaminophen in the last 3 years (1109 cases); for the HRpositive/HER2-negative subtype, $\mathrm{HRR}=0.98,95 \% \mathrm{CI}$ 0.83-1.16 for current use of $3+$ tablets per week (180 cases) compared to no use of acetaminophen in the last 3 years (757 cases); other data not shown).

\section{Discussion}

Among CTS participants who reported their detailed, current use of NSAIDs and then were followed prospectively for a median of 7 years, the association between use of specific NSAIDs and the development of invasive breast cancer or its receptor-defined subtypes differed depending on the NSAID used. In the $23 \%$ of women who reported using low-dose aspirin at least three times per week, we observed a modest $20 \%$ reduction in risk of developing HR-positive/HER2-negative breast cancer, which is likely responsible for the similar association 
Table 2 NSAID use and risk of breast cancer overall and by subtype, California Teachers Study, 2005-2012

\begin{tabular}{|c|c|c|c|c|c|c|}
\hline & & Breast cancer $^{a}$ & $\mathrm{HR}+/ \mathrm{HER} 22^{\mathrm{a}}$ & $\mathrm{HR}+/ \mathrm{HER} 2+^{\mathrm{b}}$ & HR-/HER2- ${ }^{c}$ & HR-/HER2+ ${ }^{\mathrm{d}}$ \\
\hline \multicolumn{7}{|l|}{$\overline{\text { Any NSAID }}$} \\
\hline \multirow[t]{2}{*}{ No NSAID past 3 years } & Cases, $n$ & 514 & 349 & 35 & 55 & 17 \\
\hline & HRR & 1.0 & 1.0 & 1.0 & 1.0 & 1.0 \\
\hline \multirow[t]{3}{*}{ Former/irregular } & Cases, $n$ & 154 & 105 & 11 & 12 & 5 \\
\hline & HRR & 1.04 & 1.04 & 1.11 & 0.79 & 1.03 \\
\hline & $95 \% \mathrm{Cl}$ & $0.86-1.24$ & $0.83-1.29$ & $0.56-2.20$ & $0.42-1.48$ & $0.38-2.81$ \\
\hline \multirow[t]{3}{*}{ Current, 3+ tablets/week } & Cases, $n$ & 692 & 481 & 65 & 58 & 18 \\
\hline & HRR & 0.90 & 0.91 & 1.30 & 0.77 & 0.74 \\
\hline & $95 \% \mathrm{Cl}$ & $0.80-1.01$ & $0.79-1.05$ & $0.86-1.98$ & $0.53-1.12$ & $0.38-1.45$ \\
\hline \multirow[t]{3}{*}{ Unknown } & Cases, $n$ & 97 & 63 & 9 & 13 & 4 \\
\hline & HRR & 1.16 & 1.09 & 1.73 & 1.58 & 1.45 \\
\hline & $95 \% \mathrm{Cl}$ & $0.93-1.44$ & $0.83-1.43$ & $0.83-3.61$ & $0.86-2.90$ & $0.48-4.37$ \\
\hline \multicolumn{7}{|l|}{ Low-dose aspirin } \\
\hline \multirow[t]{2}{*}{ No NSAID past 3 years ${ }^{\mathrm{e}}$} & Cases, $n$ & 514 & 349 & 35 & 55 & 17 \\
\hline & HRR & 1.0 & 1.0 & 1.0 & 1.0 & 1.0 \\
\hline \multirow{3}{*}{$\begin{array}{l}\text { No low-dose aspirin use } \\
\text { but use of } 1+\text { type(s) }\end{array}$} & Cases, $n$ & 400 & 281 & 34 & 33 & 10 \\
\hline & HRR & 0.99 & 0.93 & 1.21 & 1.19 & 2.59 \\
\hline & $95 \% \mathrm{Cl}$ & $0.82-1.19$ & $0.75-1.17$ & $0.64-2.29$ & $0.63-2.25$ & $0.75-8.94$ \\
\hline \multirow[t]{3}{*}{ Former/irregular } & Cases, $n$ & 104 & 71 & 7 & 6 & 4 \\
\hline & HRR & 0.95 & 0.88 & 1.06 & 0.70 & 1.55 \\
\hline & $95 \% \mathrm{Cl}$ & $0.75-1.19$ & $0.67-1.16$ & $0.45-2.50$ & $0.29-1.67$ & $0.48-4.99$ \\
\hline \multirow[t]{3}{*}{ Current, 3+ tablets/week } & Cases, $n$ & 338 & 230 & 33 & 31 & 10 \\
\hline & HRR & 0.84 & 0.80 & 1.37 & 0.96 & 1.06 \\
\hline & $95 \% \mathrm{Cl}$ & $0.72-0.98$ & $0.66-0.96$ & $0.81-2.32$ & $0.59-1.55$ & $0.46-2.45$ \\
\hline \multirow[t]{3}{*}{ Unknown } & Cases, $n$ & 101 & 67 & 11 & 13 & 3 \\
\hline & HRR & 0.84 & 0.73 & 2.12 & 1.61 & 0.93 \\
\hline & $95 \% \mathrm{Cl}$ & $0.62-1.14$ & $0.50-1.07$ & $0.84-5.34$ & $0.68-3.79$ & $0.19-4.68$ \\
\hline \multicolumn{7}{|l|}{ Regular-dose aspirin } \\
\hline \multirow[t]{2}{*}{ No NSAID past 3 years } & Cases, $n$ & 514 & 349 & 35 & 55 & 17 \\
\hline & HRR & 1.0 & 1.0 & 1.0 & 1.0 & 1.0 \\
\hline \multirow{3}{*}{$\begin{array}{l}\text { No regular-dose aspirin use } \\
\text { but use of } 1+\text { type(s) }\end{array}$} & Cases, $n$ & 587 & 395 & 53 & 51 & 19 \\
\hline & HRR & 0.96 & 0.90 & 1.35 & 1.19 & 2.10 \\
\hline & $95 \% \mathrm{Cl}$ & $0.80-1.16$ & $0.72-1.12$ & $0.72-2.51$ & $0.64-2.22$ & $0.65-6.82$ \\
\hline \multirow[t]{3}{*}{ Former/irregular } & Cases, $n$ & 73 & 59 & 4 & 4 & 1 \\
\hline & HRR & 1.12 & 1.27 & 1.03 & 1.03 & 0.96 \\
\hline & $95 \% \mathrm{Cl}$ & $0.84-1.50$ & $0.91-1.77$ & $0.32-3.31$ & $0.34-3.13$ & $0.11-8.30$ \\
\hline \multirow[t]{3}{*}{ Current, 3+ tablets/week } & Cases, $n$ & 170 & 119 & 18 & 14 & 3 \\
\hline & HRR & 0.97 & 0.95 & 1.68 & 1.02 & 0.84 \\
\hline & $95 \% \mathrm{Cl}$ & $0.80-1.18$ & $0.75-1.20$ & $0.90-3.17$ & $0.54-1.93$ & $0.24-3.03$ \\
\hline \multirow[t]{3}{*}{ Unknown } & Cases, $n$ & 113 & 76 & 10 & 14 & 4 \\
\hline & HRR & 1.13 & 1.04 & 1.70 & 2.21 & 2.35 \\
\hline & $95 \%$ Cl & $0.83-1.54$ & $0.72-1.52$ & $0.60-4.81$ & $0.91-5.37$ & $0.29-18.94$ \\
\hline
\end{tabular}


Table 2 NSAID use and risk of breast cancer overall and by subtype, California Teachers Study, 2005-2012 (Continued)

\begin{tabular}{|c|c|c|c|c|c|c|}
\hline \multicolumn{7}{|l|}{ Ibuprofen } \\
\hline \multirow[t]{2}{*}{ No NSAID past 3 years ${ }^{\mathrm{e}}$} & Cases, $n$ & 514 & 349 & 35 & 55 & 17 \\
\hline & HRR & 1.0 & 1.0 & 1.0 & 1.0 & 1.0 \\
\hline \multirow{3}{*}{$\begin{array}{l}\text { No ibuprofen use but } \\
\text { use of } 1+\text { type(s) }\end{array}$} & Cases, $n$ & 472 & 317 & 43 & 44 & 19 \\
\hline & HRR & 0.96 & 0.92 & 1.14 & 1.19 & 2.22 \\
\hline & $95 \% \mathrm{Cl}$ & $0.80-1.15$ & $0.74-1.15$ & $0.61-2.14$ & $0.64-2.23$ & $0.69-7.16$ \\
\hline \multirow[t]{3}{*}{ Former/irregular } & Cases, $n$ & 93 & 68 & 9 & 5 & 0 \\
\hline & HRR & 0.95 & 1.00 & 1.29 & 0.65 & \\
\hline & $95 \% \mathrm{Cl}$ & $0.74-1.23$ & $0.74-1.35$ & $0.56-2.97$ & $0.24-1.76$ & \\
\hline \multirow[t]{3}{*}{ Current, $3+$ tablets/week } & Cases, $n$ & 263 & 190 & 20 & 20 & 4 \\
\hline & HRR & 1.04 & 1.09 & 1.00 & 0.90 & 0.66 \\
\hline & $95 \% \mathrm{Cl}$ & $0.88-1.23$ & $0.90-1.34$ & $0.54-1.84$ & $0.51-1.58$ & $0.21-2.10$ \\
\hline \multirow[t]{3}{*}{ Unknown } & Cases, $n$ & 115 & 74 & 13 & 14 & 4 \\
\hline & HRR & 1.30 & 1.12 & 2.59 & 1.97 & 1.18 \\
\hline & $95 \% \mathrm{Cl}$ & $0.99-1.70$ & $0.79-1.56$ & $1.16-5.79$ & $0.90-4.31$ & $0.19-7.46$ \\
\hline \multicolumn{7}{|l|}{ Other non-steroidal } \\
\hline \multirow[t]{2}{*}{ No NSAID past 3 years ${ }^{\mathrm{e}}$} & Cases, $n$ & 514 & 349 & 35 & 55 & 17 \\
\hline & HRR & 1.0 & 1.0 & 1.0 & 1.0 & 1.0 \\
\hline \multirow{3}{*}{$\begin{array}{l}\text { No other non-steroidal use } \\
\text { but use of } 1+\text { type(s) }\end{array}$} & Cases, $n$ & 662 & 456 & 57 & 59 & 20 \\
\hline & HRR & 0.96 & 0.91 & 1.21 & 1.21 & 2.05 \\
\hline & $95 \% \mathrm{Cl}$ & $0.80-1.15$ & $0.73-1.13$ & $0.65-2.25$ & $0.65-2.26$ & $0.63-6.63$ \\
\hline \multirow[t]{3}{*}{ Former/irregular } & Cases, $n$ & 64 & 38 & 7 & 6 & 3 \\
\hline & HRR & 0.98 & 0.77 & 1.62 & 1.41 & 3.14 \\
\hline & $95 \% \mathrm{Cl}$ & $0.72-1.33$ & $0.52-1.13$ & $0.62-4.20$ & $0.54-3.64$ & $0.78-12.72$ \\
\hline \multirow[t]{3}{*}{ Current, $3+$ tablets/week } & Cases, $n$ & 96 & 75 & 8 & 4 & 0 \\
\hline & HRR & 0.79 & 0.85 & 0.97 & 0.43 & \\
\hline & $95 \% \mathrm{Cl}$ & $0.62-1.00$ & $0.64-1.13$ & $0.41-2.25$ & $0.15-1.26$ & \\
\hline \multirow[t]{3}{*}{ Unknown } & Cases, $n$ & 121 & 80 & 13 & 14 & 4 \\
\hline & HRR & 1.17 & 1.00 & 2.74 & 1.91 & 1.94 \\
\hline & $95 \% \mathrm{Cl}$ & $0.86-1.58$ & $0.69-1.45$ & $1.09-6.87$ & $0.79-4.62$ & $0.38-9.87$ \\
\hline \multicolumn{7}{|l|}{ Cox-2 inhibitor } \\
\hline \multirow[t]{2}{*}{ No NSAID past 3 years ${ }^{\mathrm{e}}$} & Cases, $n$ & 514 & 349 & 35 & 55 & 17 \\
\hline & HRR & 1.0 & 1.0 & 1.0 & 1.0 & 1.0 \\
\hline \multirow{3}{*}{$\begin{array}{l}\text { No Cox-2 inhibitor use, } \\
\text { but use of } 1+\text { type(s) }\end{array}$} & Cases, $n$ & 706 & 492 & 59 & 59 & 19 \\
\hline & HRR & 0.96 & 0.90 & 1.22 & 1.22 & 2.68 \\
\hline & $95 \% \mathrm{Cl}$ & $0.80-1.15$ & $0.72-1.12$ & $0.66-2.27$ & $0.66-2.28$ & $0.78-9.17$ \\
\hline \multirow[t]{3}{*}{ Former/irregular } & Cases, $n$ & 82 & 57 & 8 & 6 & 4 \\
\hline & HRR & 1.02 & 0.97 & 1.64 & 1.16 & 3.81 \\
\hline & $95 \% \mathrm{Cl}$ & $0.78-1.34$ & $0.70-1.34$ & $0.68-3.97$ & $0.46-2.96$ & $1.07-13.57$ \\
\hline \multirow[t]{3}{*}{ Current, $3+$ tablets/week } & Cases, $n$ & 30 & 15 & 5 & 4 & 1 \\
\hline & HRR & 0.92 & 0.63 & 2.60 & 1.74 & 1.74 \\
\hline & $95 \% \mathrm{Cl}$ & $0.63-1.34$ & $0.37-1.07$ & $0.97-7.00$ & $0.61-4.99$ & $0.22-13.66$ \\
\hline
\end{tabular}


Table 2 NSAID use and risk of breast cancer overall and by subtype, California Teachers Study, 2005-2012 (Continued)

\begin{tabular}{lllllll}
\hline Unknown & Cases, $n$ & 125 & 85 & 13 & 14 & 3 \\
& HRR & 1.19 & 1.09 & 3.08 & 1.94 & 0.88 \\
& $95 \% \mathrm{Cl}$ & $0.88-1.61$ & $0.75-1.58$ & $1.21-7.88$ & $0.79-4.75$ & $0.15-5.22$ \\
\hline
\end{tabular}

${ }^{a}$ Cox regression models used age as the time metric, were stratified by age at the follow-up questionnaire, and were adjusted for age at menarche, parity and age at first full-term pregnancy, total months breastfeeding their offspring, history of a benign breast biopsy, family history of breast cancer (mother or sister), strenuous plus moderate physical activity, alcohol consumption, body mass index, menopausal status and hormone therapy use, and (except for "Any NSAID") all of the other NSAIDS in the table (for each type: never past 3 years, former/irregular, current $3+$ tablets/week, unknown). ${ }^{b}$ Cox regression models used age as the time metric, were stratified by age at the follow-up questionnaire, and were adjusted for parity and age at first full-term pregnancy, body mass index, and (except for "Any NSAID") all of the other NSAIDS in the table. ${ }^{C}$ Cox regression models used age as the time metric, were stratified by age at the follow-up questionnaire, and were adjusted for race, alcohol consumption and its interaction with time-dependent age, and (except for "Any NSAID") all of the other NSAIDS in the table. ${ }^{\mathrm{d}}$ Cox regression models used age as the time metric, were stratified by age at the follow-up questionnaire, and were adjusted for total months breastfeeding their offspring, history of a benign breast biopsy, and (except for "Any NSAID") all of the other NSAIDS in the table. "Included aspirin, low-dose aspirin, ibuprofen, Cox-2 inhibitor, and other NSAIDs currently used regularly (at least once a week) reported on the 10-year follow-up questionnaire. NSAID non-steroidal anti-inflammatory drug, HRR hazard rate ratio, $\mathrm{Cl}$ confidence interval

observed between NSAID use and risk of breast cancer overall. This association persisted after consideration of other breast cancer risk factors including use of HT and prior history of myocardial infarction. This association is intriguing because no such association was observed with the use of regular-dose aspirin $(325 \mathrm{mg})$. We suspect that this could relate to the more regular use of low-dose aspirin for cardioprotection, as opposed to a more sporadic pattern of use of regular-dose aspirin to relieve pain. We did not observe any apparent modification of the low-dose aspirin effect by overweight status, nor did we observe stronger associations in women who were likely to be longer-term users, having reported using aspirin 10 years earlier, at baseline. This association should be re-examined in cohorts with larger numbers of incident breast cancers in which HR and HER2 status are recorded.

The three studies published previously that assessed HR-defined and HER-2-defined subtypes differed in the definitions of medication dose and duration of use, limiting our ability to compare the results of those studies to ours. The Nurses' Health Study [10] conducted the most comprehensive assessment of NSAID use in relation to receptor-defined subtypes, finding no association between breast cancer and use of non-aspirin NSAIDs or acetaminophen. They defined regular users of aspirin as those using two or more reduced tablets per week, but did not distinguish low-dose from regular-dose formulations. Across the four HR/HER2-defined subtypes, the analyses of which were based on fewer cases than in the present study, statistically significant protective effects against HR-positive/HER2-negative breast cancer were detected ( $n=341$ cases), regardless of the duration of reported use $(10+$ years of use: relative risk $(R R)=0.66$, 95\% CI 0.49-0.89, fewer than 10 years of use: $R R=0.75$, 95\% CI 0.58-0.96). They did not observe any association with the HR-positive/HER2-positive subtype $(\mathrm{n}=74$ cases, $10+$ years of use: $R R=1.47,95 \%$ CI $0.76-2.82$; fewer than 10 years of use: $R R=1.40,95 \%$ CI $0.79-2.51$ ) or for the receptor-negative subtypes ( $\mathrm{n}=174$ cases), or for breast cancer overall $[16,17]$. This pattern of association is similar to what we have shown here for CTS participants.

In the Nashville Breast Health Study [12], a casecontrol study, the authors reported statistically significant protective effects of regular use of any NSAID against the risk of all receptor-defined subtypes, with a reduced odds ratio (OR) for HR-positive/HER2-negative cancer $(\mathrm{OR}=0.71,95 \% \mathrm{CI} 0.56-0.88)$ similar to the HRR reported here; this was limited to overweight women with BMI of at least $25 \mathrm{~kg} / \mathrm{m}^{2}$ [12]. Our results did not suggest an interaction with overweight status. In the Western New York Exposures and Breast Cancer Study [11], another case-control study, the authors reported a statistically significant reduction in risk of breast cancer overall associated with aspirin use, which did not persist for any subtype examined, including the four receptordefined subtypes.

Our key finding is related to low-dose aspirin and not to regular-dose aspirin. Women who reported using low-dose aspirin were more likely to take it more than three times per week or daily, possibly for cardiovascular disease prevention. In our prior analysis of NSAID use reported at baseline by CTS participants and development of subsequent breast cancer [18], we could not distinguish between low-dose and regular-dose aspirin as we did not inquire about dose in the baseline questionnaire. In that analysis we found no association between use of aspirin or ibuprofen more than once weekly and risk of breast cancer overall, but risk of HR-negative breast cancer was increased with 5 or more years of daily aspirin use ( $R R=1.81,95 \%$ CI $1.12-2.92)$ [18]. In the current assessment, we did not see any association between breast cancer and use of regular-dose aspirin, nor did we detect any significant increase in risk of any breast cancer subtype with any aspirin use, regardless of dose. Our assessment of probable long-term users (women who used aspirin at baseline and at the 10-year follow-up) showed that these women had a similar risk of breast cancer overall and of the HR-positive/HER2- 
negative subtype as those who reported current use at the 10-year follow-up.

Our finding of an inverse association between use of $3+$ low-dose aspirin tablets/week and risk of breast cancer overall is consistent with the findings of several other observational studies that did not separately examine HR-defined and HER2-defined subtypes. The largest and most detailed prospective study, the VITAL cohort [19], found that women taking $81 \mathrm{mg}$ low-dose aspirin for $\geq 4$ days per week had a more pronounced reduction in risk of breast cancer overall $(\mathrm{HRR}=0.65$, 95\% CI 0.43-0.97) after 10 years of follow up [20] than we observed here. The results from a large prospective study using the UK General Practice Database [21] showed a statistically significant decreased risk of breast cancer among women who took low-dose aspirin daily for at least 1 year (OR $=0.67,95 \%$ CI $0.51-0.89)$, suggesting only a short duration of use was needed for a reduction in risk to become apparent.

In contrast to these studies, in the Women's Health Initiative observational study [22] risk of breast cancer overall was reduced $21 \%$ in women who took regulardose aspirin but not in women who took low-dose aspirin. Our findings are not consistent with the Women's Health Study, a randomized clinical trial of the use of low-dose $(100 \mathrm{mg})$ aspirin every other day, a frequency that would have mapped to the low end of our category defining regular use as at least three tablets weekly. After 10 years, the risk of breast cancer overall was unchanged $(\mathrm{RR}=0.98,95 \%$ CI $0.97-1.09, p=0.68)$ [3] among the women randomized to low-dose aspirin. In a later subanalysis the investigators reported no association according to breast tumor characteristics such as size, histology, grade, or differentiation [17]. Altogether, these studies support the notion that use of low-dose aspirin at least three times per week, or perhaps daily, modestly reduces overall breast cancer risk by about $20-25 \%$. Our results add to this evidence base, suggesting that the reduction in risk occurs mainly in the HR-positive/HER2negative subtype.

The biological mechanism by which low-dose aspirin could function as a chemopreventive agent against HRpositive/HER2-negative breast cancer, but not other breast cancer subtypes, is not yet clear. A consistent lowering of COX-2 and prostaglandin activity could prevent or slow carcinogenesis in a number of ways, at the tumor level, by interfering with DNA adduct formation [23], inhibiting tumor angiogenesis $[4,24,25]$, or promoting apoptosis [26]. Recent data examining serum circulating inflammatory markers among healthy subjects ages 55-74 years did not indicate that regular-dose aspirin use is associated with any of 78 circulating markers, calling into question the relevance of circulating levels of immune markers [27] and raising the possibility of a more local immune effect. Alternatively, as prostaglandins may upregulate production of circulating estrogens via aromatase [28, 29], daily use of lowdose aspirin may inhibit aromatase, which could reduce levels of key hormones and thereby impact initiation or promotion of estrogen-sensitive tumors [18, 30, 31]. This analysis and that from the Nurses' Health Study [10] indicated protective effects of consistent aspirin use against the risk of HR-positive tumors, but only those that are also HER2-negative. On the other hand, elevated COX-2 levels have been detected in triple-negative tumors [32].

Strengths of this study include the complete and accurate prospective ascertainment of HER2-defined breast cancer development based on routine linkage of the cohort to the statewide cancer registry, linkage to hospital discharge summary data to confirm any previous myocardial infarction, and a median of 7 years of follow up. Our study also had limitations. The total number of breast cancer cases was greater than was available in previously published analyses, but the limited numbers available for subtype-specific analyses meant that these were exploratory. It is possible that women who regularly take low-dose aspirin differed from women who did not, based on important health parameters (other than history of myocardial infarction or comorbid diabetes mellitus), resulting in residual and unmeasured confounding. For instance, women who regularly take low-dose aspirin could engage in more health-conscious behavior than non-users or infrequentusers. Like most observational studies, we were only able to measure NSAID exposure as "snapshots" of exposure at the time women completed their surveys. We were limited in evaluating possible confounding by indication for cardiovascular disease that did not result in hospitalization for myocardial infarction. Finally, this population is not representative of the general population of California women or women across the USA, particularly with respect to educational status; thus, it is uncertain how generalizable our findings are to the broader population, particularly non-white women and women born outside the USA. At cohort inception in 1996, CTS participants had incidence rates of breast cancer that were over 50\% higher than those for agematched and race-matched women in California [14], which probably reflects higher prevalence of risk factors including hormone therapy use, alcohol consumption and particular reproductive profiles.

In summary, our study strongly supports the need for further, perhaps experimental, study of low-dose aspirin as a widely available, inexpensive chemopreventive option for the most common subtype of breast cancer, the HR-positive/HER2-negative subtype. Our study adds to the existing evidence on this topic, showing that 
previously reported associations between low-dose aspirin use and risk of breast cancer overall may be driven by a more specific association with this hormonesensitive and HER2-negative breast cancer subtype. Furthermore, it suggests that previously reported associations using measures that combined low-dose aspirin use (more likely to be daily or more frequent) with regular aspirin use should reassess these associations. Future studies of aspirin and breast cancer must be able to distinguish low-dose from other formulations and to assess risks separately by molecularly defined subtype. Such studies should not only detail this chemopreventive potential but should also quantify any side effects associated with regular low-dose aspirin use.

\section{Conclusions}

For $23 \%$ of women who reported using low-dose aspirin at least three times per week, we observed a modest $20 \%$ reduction in risk of developing HR-positive/HER2-negative breast cancer, which is likely responsible for the similar association observed for breast cancer overall. No such association was observed for use of regulardose aspirin $(325 \mathrm{mg})$ or other NSAIDs. We suspect that our observations could relate to the pattern of daily use of low-dose aspirin for prevention, as opposed to more sporadic patterns of use to relieve pain. Our data are intriguing as regards the role of low-dose aspirin in breast cancer prevention but this question should be revisited in cohorts with larger numbers of incident breast cancers, in which HR and HER2 status are also recorded.

\section{Acknowledgements \\ The authors would like to thank the CTS Steering Committee members, who are responsible for the formation and maintenance of the cohort within which this study was conducted. The ideas and opinions expressed herein are those of the author(s) and endorsement by the State of California Department of Public Health, the National Cancer Institute, and the Centers for Disease Control and Prevention or their Contractors and Subcontractors is not intended nor should be inferred.}

\section{Funding}

This study was supported by grant R01 CA77398 from the National Cancer Institute, and contract 97-10500 from the California Breast Cancer Research Fund. The collection of data on cancer incidence used in this study was supported by the California Department of Public Health as part of the statewide cancer reporting program mandated by California Health and Safety Code Section 103885; the National Cancer Institute's Surveillance, Epidemiology and End Results Program under contract HHSN261201000036C awarded to the Cancer Prevention Institute of California, contract HHSN261201000035C awarded to the University of Southern California, and contract HHSN261201000034C awarded to the Public Health Institute; and the Centers for Disease Control and Prevention's National Program of Cancer Registries, under agreement \#1U58 DP000807-01 awarded to the Public Health Institute.

\section{Availability of data and materials}

The datasets used and/or analyzed in the current study are available from the corresponding author on reasonable request.

\section{Authors' contributions}

CAC, AJC, JVL, NTC, and LB contributed to study concept and design and data analysis and interpretation. AJC carried out the statistical analysis. CAC, AJC, JVL, NTC, SLN, and LB contributed to the drafting of the manuscript, and critical revision of the manuscript for important intellectual content. LB supervised the study. All authors read and approved the final manuscript.

\section{Authors' information}

Since writing this paper, Dr. Clarke has taken a position at GRAIL, Inc.

\section{Competing interests}

CAC received research funding via her institution from Genentech/Roche for an unrelated study. Since completing this work, CAC has taken a new position at GRAIL, Inc.

\section{Consent for publication}

Not applicable.

\section{Ethics approval and consent to participate}

The study was approved by the institutional review boards of the Cancer Prevention Institute of California, the University of Southern California, the University of California, Irvine, and City of Hope National Medical Center. Each participant indicated her consent to become a member of the CTS by submitting the first questionnaire (which informed them of their rights as a study participant on the first page) and each additional questionnaire. Each participating institution's institutional review board approved this passive method of obtaining consent. Eighteen women indicated that they wished to restrict their data to analyses of breast cancer and these participants are excluded from research into other types of cancer.

\section{Publisher's Note}

Springer Nature remains neutral with regard to jurisdictional claims in published maps and institutional affiliations.

\section{Author details}

${ }^{1}$ Cancer Prevention Institute of California, 2201 Walnut Ave. Suite 300, Fremont, CA 94538, USA. ${ }^{2}$ Department of Health Research and Policy and the Stanford Cancer Institute, Stanford University School of Medicine, 150 Governor's Lane, HRP Redwood Bldg, Stanford, CA 94305, USA. ${ }^{3}$ Department of Population Sciences, Beckman Research Institute of City of Hope, 1500 East Duarte Rd, Duarte, CA 91010, USA. ${ }^{4}$ Division of Research, Kaiser Permanente, 2000 Broadway, Oakland, CA 94612, USA.

Received: 18 November 2016 Accepted: 29 March 2017

Published online: 01 May 2017

\section{References}

1. Guirguis-Blake JM, Evans CV, Senger CA, Rowland MG, O'Connor EA, Whitlock EP. Aspirin for the primary prevention of cardiovascular events: a systematic evidence review for the U.S. Preventive Services Task Force Rockville: Agency for Healthcare Research and Quality. Report No.: 1305195-EF-12015; 2015.

2. Chubak J, Kamineni A, Buist DSM, Anderson ML, Whitlock EP. Aspirin use for the prevention of colorectal cancer: an updated systematic evidence review for the U.S. Preventive Services Task Force. Rockville: Agency for Healthcare Research and Quality. Report No.: 15-05228-EF-1; 2015.

3. Cook NR, Lee I, Gaziano JM, Gordon D, Ridker PM, Manson JE, Hennekens CH, Buring JE. Low-dose aspirin in the primary prevention of cancer: the Women's Health Study: a randomized controlled trial. JAMA. 2015;294:47-55.

4. Takkouche B, Regueira-Méndez C, Etminan M. Breast cancer and use of nonsteroidal anti-inflammatory drugs: a meta-analysis. J Natl Cancer Inst. 2008;100:1439-47.

5. Zhong $S$, Chen L, Zhang $X, Y u$ D, Tang J, Zhao J. Aspirin use and risk of breast cancer: systematic review and meta-analysis of observational studies. Cancer Epidemiol Biomarkers Prev. 2015;24:1645-55.

6. Dent R, Trudeau M, Pritchard KI, Hanna WM, Kahn HK, Sawka CA, Lickley LA, Rawlinson E, Sun P, Narod SA. Triple-negative breast cancer: clinical features and patterns of recurrence. Clin Cancer Res. 2007:13:4429-34.

7. Lin NU, Vanderplas A, Hughes ME, Theriault RL, Edge SB, Wong YN, Blayney DW, Niland JC, Winer EP, Weeks JC. Clinicopathologic features, patterns of recurrence, and survival among women with triple-negative breast cancer in the National Comprehensive Cancer Network. Cancer. 2012;118:5463-72.

8. Millikan RC, Newman B, Tse CK, Moorman PG, Conway K, Dressler LG, Smith LV, Labbok MH, Geradts J, Bensen JT, et al. Epidemiology of basal-like breast cancer. Breast Cancer Res Treat. 2008;109:123-39. 
9. Phipps Al, Chlebowski RT, Prentice R, McTiernan A, Stefanick ML, WactawskiWende J, Kuller LH, Adams-Campbell LL, Lane D, Vitolins M, et al. Body size, physical activity, and risk of triple-negative and estrogen receptor-positive breast cancer. Cancer Epidemiol Biomarkers Prev. 2011;20:454-63.

10. Zhang X, Smith-Warner SA, Collins LC, Rosner B, Willett WC, Hankinson SE. Use of aspirin, other nonsteroidal anti-inflammatory drugs, and acetaminophen and postmenopausal breast cancer incidence. J Clin Oncol. 2012;30:3468-77.

11. Brasky TM, Bonner MR, Moysich KB, Ambrosone CB, Nie J, Tao MH, Edge SB, Kallakury BV, Marian C, Goerlitz DS, et al. Non-steroidal anti-inflammatory drugs (NSAIDs) and breast cancer risk: differences by molecular subtype. Cancer Causes Control. 2011;22:965-75.

12. Cui Y, Deming-Halverson SL, Shrubsole MJ, Beeghly-Fadiel A, Cai H, Fair AM, Shu X-O, Zheng W. Use of nonsteroidal anti-inflammatory drugs and reduced breast cancer risk among overweight women. Breast Cancer Res Treat. 2014;146:439-46.

13. Marshall SF, Clarke CA, Deapen D, Henderson K, Largent J, Neuhausen SL, Reynolds P, Ursin G, Horn-Ross PL, Stram DO, et al. Recent breast cancer incidence trends according to hormone therapy use: the California Teachers Study cohort. Breast Cancer Res. 2010;12:R4.

14. Bernstein L, Allen M, Anton-Culver H, Deapen D, Horn-Ross PL, Peel D, Pinder R, Reynolds P, Sullivan-Halley J, West D, et al. High breast cancer incidence rates among California teachers: results from the California Teachers Study (United States). Cancer Causes Control. 2002;13:625-35.

15. Kwong SL PC, Morris CR, et al. Cancer in California: 1988-1999. Sacramento, CA: California Department of Health Services, Cancer Surveillance Section; 2001

16. Cao Y, Nishihara R, Wu K, Wang M, Ogino S, Willett WC, Spiegelman D, Fuchs CS, Giovannucci EL, Chan AT. Population-wide impact of long-term use of aspirin and the risk for cancer. JAMA Oncol. 2016;2:762-9.

17. Zhang SM, Cook NR, Manson JE, Lee IM, Buring JE. Low-dose aspirin and breast cancer risk: results by tumour characteristics from a randomised trial. Br J Cancer. 2008;98:989-91.

18. Marshall SF, Bernstein L, Anton-Culver H, Deapen D, Horn-Ross PL, Mohrenweiser H, Peel D, Pinder R, Purdie DM, Reynolds P, et al. Nonsteroidal anti-inflammatory drug use and breast cancer risk by stage and hormone receptor status. J Natl Cancer Inst. 2005;97:805-12.

19. Ready A, Velicer CM, McTiernan A, White E. NSAID use and breast cancer risk in the VITAL cohort. Breast Cancer Res Treat. 2008;109:533-43.

20. Bosco JL, Palmer JR, Boggs DA, Hatch EE, Rosenberg L. Regular aspirin use and breast cancer risk in US black women. Cancer Causes Control. 2011; 22:1553-61.

21. García Rodríguez LA, González-Pérez A. Risk of breast cancer among users of aspirin and other anti-inflammatory drugs. Br J Cancer. 2004;91:525-9.

22. Harris RE, Chlebowski RT, Jackson RD, Frid DJ, Ascenseo JL, Anderson G, Loar A, Rodabough RJ, White E, McTiernan A. Breast cancer and nonsteroidal anti-inflammatory drugs: prospective results from the Women's Health Initiative. Cancer Res. 2003;63:6096-101.

23. Harris RE, Robertson FM, Abou-Issa HM, Farrar WB, Brueggemeier R. Genetic induction and upregulation of cyclooxygenase (COX) and aromatase (CYP19): an extension of the dietary fat hypothesis of breast cancer. Med Hypotheses. 1999;52:291-2.

24. Ashok V, Dash C, Rohan TE, Sprafka JM, Terry PD. Selective cyclooxygenase-2 (COX-2) inhibitors and breast cancer risk. Breast. 2011;20:66-70.

25. Kirsh VA, Kreiger N, Cotterchio M, Sloan M, Theis B. Nonsteroidal antiinflammatory drug use and breast cancer risk: subgroup findings. Am J Epidemiol. 2007;166:709-16.

26. Shiff SJ, Rigas B. The role of cyclooxygenase inhibition in the antineoplastic effects of nonsteroidal antiinflammatory drugs (NSAIDs). J Exp Med. 1999;190:445-50.

27. Lang Kuhs KA, Hildesheim A, Trabert B, Kemp TJ, Purdue MP, Wentzensen N Katki HA, Pinto LA, Loftfield E, Safaeian M, et al. Association between regular aspirin use and circulating markers of inflammation: a study within the Prostate, Lung, Colorectal, and Ovarian Cancer Screening Trial. Cancer Epidemiol Biomarkers Prev. 2015;24:825-32.

28. Davies G, Martin LA, Sacks N, Dowsett M. Cyclooxygenase-2 (COX-2), aromatase and breast cancer: a possible role for COX-2 inhibitors in breast cancer chemoprevention. Ann Oncol. 2002;13(5):669-78.

29. Zhao Y-s, Zhu S, X-w L, Wang F, Hu F-l, Li D-d, Zhang W-c, Li X. Association between NSAIDs use and breast cancer risk: a systematic review and metaanalysis. Breast Cancer Res Treat. 2009;117:141-50.
30. Gierach GL, Lacey Jr JV, Schatzkin A, Leitzmann MF, Richesson D, Hollenbeck AR, Brinton LA. Nonsteroidal anti-inflammatory drugs and breast cancer risk in the National Institutes of Health-AARP Diet and Health Study. Breast Cancer Res. 2008;10:R38.

31. Terry MB, Gammon MD, Zhang FF, Tawfik H, Teitelbaum SL, Britton JA, Subbaramaiah K, Dannenberg AJ, Neugut Al. Association of frequency and duration of aspirin use and hormone receptor status with breast cancer risk. JAMA. 2004;291:2433-40.

32. Mosalpuria K, Hall C, Krishnamurthy S, Lodhi A, Hallman DM, Baraniuk MS, Bhattacharyya A, Lucci A. Cyclooxygenase-2 expression in nonmetastatic triple-negative breast cancer patients. Mol Clin Oncol. $2014 ; 2: 845-50$

\section{Submit your next manuscript to BioMed Central and we will help you at every step:}

- We accept pre-submission inquiries

- Our selector tool helps you to find the most relevant journal

- We provide round the clock customer support

- Convenient online submission

- Thorough peer review

- Inclusion in PubMed and all major indexing services

- Maximum visibility for your research

Submit your manuscript at www.biomedcentral.com/submit
Biomed Central 